\title{
HUME E $O$ EMPIRISMO NA MORAL
}

\author{
Adriano Naves de Brito \\ U niversidade Federal de Goiás \\ adriano@fchf.ufg.br
}

\begin{abstract}
RESU M 0: 0 que pretendo defen der neste texto é que uma posição empirista na moral é compatível com uma pretensão de validade intersubjetiva de juízos morais. Essa pretensão deve, nesse caso, estar calcada na naturalização dos fundamentos da moralidade, mas tem de conviver com limites acerca da justificação de enunciados de valor. Para defender esse ponto, sirvo-meda filosofia moral de H ume, como ele a expôs no seu texto U ma investigação sobre os princípios da moral. $\mathrm{N}$ o que diz respeito à filosofia de $\mathrm{H}$ ume, o objetivo deste texto é explicitar o caráter empírico seja de seu método de investigação da moral, seja do princípio que para ela ele encontra.
\end{abstract}

Palavras-chave: juízos morais, justificação moral, H ume, empirismo.

O que denominamos "mundo empírico" está caracterizado pela contingência. As ciências tratam de encontrar regularidades e formular princípios para essas contingências, demodo que podemos chegar a ver o mundo dos fatos como um todo mais ou menos ordenado. M esmo que não devamos falar aqui de necessidade, a investigação da natureza com inspiração empirista não nos deixa às cegas a respeito da ordenação do mundo. Estamos autorizados a prever e a tirar conclusões sobre os eventos naturais a partir de leis e princípios ordenadores. Mas desde que, para isso, nossa fonte sejam os fatos, os fatos empíricos.

Projetada para a moral, essa concepção empirista nos leva a uma incômoda, e aparentemente paradoxal, inversão. Se há algo para investigar a propósito da moral, então, sob a perspectiva do empirismo, isto deveria estar no mundo e poder ser, como tudo o mais, objeto de uma experiência; isto é, deveria ser empírico. O ra, no que concerne à moral, aquilo de que podemos ter experiência são os comportamentos humanos. Por conseguinte, se tomarmos a 
sério o método empirista para uma investigação da moral, então não a começaremos pelo estudo dos princípios mais altos que qualquer sistema moral nos possa apresentar, mas pela investigação do comportamento dos homens em sociedade. Será da descrição do comportamento humano que se poderá inferir quais são os padrões morais que a nossa espécie, digamos assim, por natureza adota.

0 que incomoda neste procedimento metodológico de investigação é que a moralidade estaria fundada em nossos comportamentos e não eles na moralidade, como justamente se espera que fosse o caso. A inversão desarma a moral de seu aparato normativo. Sob essa perspectiva, considerando que a moral dizcomo nos devemos comportar, isso se poderia legitimar apenas por uma acurada descrição de como naturalmente estamos inclinados a agir, ou ainda, por uma descrição do que estamos inclinados a preferir quando temos escolha, o que ocorre, por exemplo, nas ações que faz sentido submeter ao tribunal da moral.

A linha divisória que separa os reinos do dever e do ser é suprimida em benefício do que simplesmente é, se reduzimos as fontes de conhecimento à experiência. Embora possamos apreender empiricamente a norma, como lei escrita, por exemplo, isso não significa ter uma experiência do dever. 0 dever se apresenta à experiência apenas como motivo para uma ação, o que corresponderia, na anal ogia com as ciências naturais, a ser a sua causa. E se 0 método de investigação compele à aceitação unicamente do que se manifesta aos sentidos, então só nos restaria considerar como dever aquilo que de fato, no plano da causalidade empírica, motiva o agir humano.

A isso chamamos de nossas inclinações naturais e seriam elas o objeto da investigação moral de cunho empirista. No âmbito dessa opção metodológica para o estudo da moralidade, podese edificar a concepção de que não importa a convicção que as sociedades apliquem a pregação de valores morais, el es não se afirmarão, caso não estejam em consonância com aquilo que somos, quer dizer, com nossa constituiçãa como seres da natureza. Sem a força das motiva- 
ções, digamos, naturais, o dever é apenas uma quimera, uma miragem em paisagens metafísicas. C ontudo, postular que o dever esteja amparado em inclinações soa como incumbir a raposa de cuidar do galinheiro. Pode até ser que o faça, mas isso dependerá das circunstâncias de sua fome. Como pode sobreviver a moral a esse relativismo?

A despeito da inversão, no plano dos fundamentos, entre moralidade e comportamento, não é certo que a concepção empirista de moral seja inexoravel mente relativista. Ela pode muito bem almejar a um universalismo apostando na naturalização dos alicerces da moralidade. Quero defender, a seguir, que este é precisamente o caso da filosofia moral de Hume. Seu ceticismo quanto às fontes não empíricas para a moral, não deve ser exacerbado ao ponto de se convertê-lo em descrença na existência de princípios morais não relativos.

Proponho-me a apresentar o cerne da filosofia moral de H ume, destacando o que, creio, podemos denominar seu "universalismo empírico", mas mostrando também, ao final, os limites de sua concepção na justificação da pretensão de validade de nossos juízos de valores.

\section{0 problema}

Pouco antes de sua morte, David H ume declarou ser U ma investigação sobre os princípios da moral o que de melhor ele teria escrito. Publicado em 1751, o livro é uma substancial reelaboração do livro três de seu Tratado da natureza humana. N otável em vários aspectos, sobretudo pelo estilo elegante mas acessível, o tema central do texto é a análise do mérito pessoal (personal merit) e das virtudes. $\mathrm{N}$ ão obstante, a questão de fundo com a qual se confronta H ume é a que se refere à investigação da "verdadeira origem da moral". A afirmação pede esclarecimentos e sobre isso me quero deter brevemente. 
H ume considera ser a moral um fato. Com isso entende que "não é concebível que alguma criatura humana possa seriamente acreditar que todos os caracteres e ações sejam igualmente dignos da estima e consideração de todas as pessoas." (Hume,1995, p.20). O fato está, pois, em que haja juízos morais, ou seja, em que haja juízos que enunciam estima por certas ações, bem como juízos que enunciam reprovação e indignação por outras ações.

O ra, que haja tais juízos é mesmo incontestável, mas que relevância poderiam ter eles para a moral se expressassem tãosomente nossas disposições subjetivas para com as ações alheias? 0 alegado fato da moral parece exigir mais para a sua existência do que a mera ocorrência de juízos de aprovação e reprovação. Parece exigir daqueles que enunciam tais juízos que tenham, ao enunciálos, al guma preten são de validade objetiva; quer dizer, que pretendam ser tais juízos a expressão de preferências bem fundadas e, por isso, válidas para muitos e, na melhor das hipóteses, para todos quantos julguem sob as mesmas circunstâncias.

Sem esse elemento de legitimação, juízos morais seriam tão constrangedores quanto juízos estéticos, que transmitem nossa aprovação ou reprovação acerca de um objeto, mas nada exigem daqueles a quem estão endereçados. Ao contrário da estética, a moral vincula os envolvidos num jogo de exigências mútuas. Portanto, o fato de que haja uma moral não está apenas na existência de juízos de valores, mas sobretudo em que estes juízos sejam exigências para os implicados. Se, do ponto de vista moral, aprovo uma ação, então estou a dizer que quero que ela se realize. M ais ainda, expresso meu desejo - e disposição de ver tal desejo realizado - de que, em semelhantes circunstâncias, ação de igual natureza seja realizada. Se, ao contrário, reprovo determinada ação, exijo que ela não se realize, ou que outras equival entes não sejam levadas a termo.

Que tal teia de exigências mútuas exista parece-me também um fato e com isso concederíamos a H ume o seu ponto sobre a realidade da moral. 0 problema seria agora determinar em que 
bases são feitas as exigências expressas nos juízos morais. Q ual seria o fundamento para esses juízos? Em outras palavras, de onde tiram eles a sustentação para a sua pretensão de validadee, por conseguinte, para a sua força constrangedora?

H ume identifica na tradição filosófica dois candidatos a fundamento da moralidade: os sentimentos e a razão. M as a controvérsia a propósito dos fundamentos da moral não será decidida por ele em favor nem de um, nem de outro desses elementos. Ambos razão e sentimentos -, mesmo que em medidas distintas, admite H ume, tomam parte em nossas deliberações de ordem moral e the dão sustentação.

É provavel que a sentença final que julga caracteres e ações como amáveis ou odiosos, louváveis ou repreensíveis, aquilo que lhes impõe a marca da honra ou da infâmia, da aprovação ou da censura, aquilo que torna a moralidade um princípio ativo e faz da virtude nossa felicidade e do vício nossa miséria -é provável, eu dizia, que essa sentença final se apóie em algum sentido interno ou sentimento que a natureza tornou universal na espécie inteira. Pois que outra coisa seria capaz de uma influência desse tipo? Contudo, para preparar o caminho para tal sentimento e prover um discernimento apropriado de seu objeto, descobrimos que é freqüentemente necessário que muitos raciocínios o precedam, que distinções sutis sejam traçadas, conclusões corretas extraídas, comparações distantes efetuadas, relações complexas examinadas e fatos gerais estabelecidos e verificados. (H U ME, 1995, p. 23-24)

O sentimento aquiesce ou reprova, mas a razão pode prestar sua assistência para que seja produzido no sentimento a apropriada reação. A analogia com a arte está à mão e éo próprio H ume quem se encarrega de aproximar esse jogo entre sentimento e razão daquilo que ocorre na apreciação estética. $\mathrm{N}$ ão podemos provocar uma sensação estética para a qual não exista em nossa humana sensibilidade uma adequada estrutura de recepção. 0 efeito senti- 
mental que nos provocam as cores está limitado não só pelo espectro de ondas que nossos olhos conseguem perceber, mas também pelo espectro de emoções que somos capazes de experimentar. C ontudo, é possível refinar nosso aparato receptivo para fazê-lo dirigir a atenção para os matizes mais delicados e para as relações mais sutis.

A razão opera na moral e na arte, sobre aquilo que já está disponível em nossa constituição natural. Sobre isso é que se apóiam os juízos de assentimento ou reprovação. Para dizermos com H ume, apóiam-se sobre "algum sentido interno ou sentimento que a natureza tornou universal na espécie inteira". 0 que garante, pois, validade intersubjetiva aos juízos morais dos diferentes agentes é o fato de possuírem todos os agentes a mesma natureza. A universalidade pretendida pelos que tomam parte da rede moral de mútuas exigências é admitida por H ume com o recurso à naturalização dos fundamentos morais.

Se queremos agora investigar os princípios da moral, então temos de dirigir nossos instrumentos de análise à sua verdadeira origem, quer dizer, à análise da natureza humana. U ma vez conhecida a nossa natureza no que tange aos seus princípios relativos à moral, e podemos dizer, em seus princípios relativos ao modo como se comportam nossos sentimentos morais, então "será fácil perceber em que medida tanto o sentimento como a razão figuram em todas as determinações dessa natureza" (Hu ME, 1995, p. 24). Há, para a consecução dessa tarefa, um método escolhido por H ume.

\section{0 método}

0 método humeano será antes de tudo empírico. E sobre o empirismo já se disse o suficiente acima. Para recuperar o essencial, numa investigação de cunho empirista, a fonte de conhecimento serão sempre os fatos. O ra, o problema posto à investigação humeana sobre a moral é determinar a verdadeira origem de seus 
princípios. Se esse problema tem de ser resolvido mediante o uso de um método empírico, então isso não será possível, isto é, não chegaremos a ter qualquer conhecimento dos princípios buscados se deles não tivermos alguma manifestação empiricamente perceptível.

Pensemos por um momento no que são princípios. Podemos pensar neles como proposições primitivas de um sistema, a partir das quais outras poderiam ser inferidas. Considerando os princípios nessa acepção, chegaríamosa eles mediante, por exemplo, a ref lexão sobre proposições inferiores. Para a filosofia moral exercida sob os cânones do empirismo, este caminho está vedado. Não lidaríamos aí com fatos, mas apenas com proposições (e isso a despeito das opiniões de Russell sobre elas).

O s princípios, no entanto, podem ser tomados também como causas de uma ação, e se os concebemos assim, já os tornamos acessíveis como dados empíricos. M esmo que não possamos percebêlos diretamente, tem de ser possível perscrutá-los por meio de seus efeitos. De fato, princípios morais nos podem ser revelados pelo que produzem, a saber, nossos sentimentos de aprovação ou reprovação. São esses sentimentos os fatos mais pal páveis que temos à disposição para averiguar quais são as nossas mais autênticas inclinações naturais concernentes à moralidade, inclinações que constituem a sua verdadeira origem, ou, em outros termos, aquilo que causa em nós o que submetemos ao título geral de "moral".

A investigação de H ume acerca dos sentimentos morais passa, inicial mente, por um procedimento de identificação dos elementos do seu conjunto. Hume dedicará parte significativa do esforço despendido, no livro que aqui temos em vista, ao levantamento das qualidades que merecem a nossa aprovação, bem como daquelas que são objeto de nossa aversão. Em suas palavras:

Esforçar-nos-emos para seguir um método bastante simples: vamos analisar o complexo de qualidades mentais que constituem aquilo que, na vida cotidiana, chamamos de mérito pessoal; vamos considerar todos os atributos 
do espírito que fazem de alguém um objeto seja de estima e afeição, seja de ódio e desprezo; todos os hábitos, sentimentos ou faculdades que, atribuídos a uma pessoa qualquer, implicam ou louvor ou censura, e poderiam figurar em algum panegírico ou sátira de seu caráter e maneiras. (HUME, 1995, p. 25)

No tocante a esse ponto, Hume imagina poder orientar a investigação pela natureza da própria linguagem, pois bastaria "a mínima familiaridade com o idioma para nos orientar, sem qualquer raciocínio, na coleta e arranjo das qualidades humanas que são estimáveis ou censuráveis" (H u me, 1995, p. 25). H ume confia que, observando o uso de certas palavras para qualidades morais, poderse-ia facilmente identificar o sentimento que a ela se liga.

N ão está em questão que, ligados a certos conceitos, devemos esperar encontrar sempre determinados sentimentos. Trata-se apenas de um procedimento descritivo, muito embora -e esse é um importante pressuposto para ele - H ume acredite que entre os homens as variações a respeito da ligação entre sentimentos e conceitos morais sejam pouco expressivas. A pretensão pode bem ser ingênua e, para ficar em apenas um crítico, a análise de N ietzsche, na sua $G$ enealogia da moral, sobre a origem dos valores que exprimimos nos conceitos morais parece suficientemente contundente para desacreditarmos no rigor dessa via de aproximação aos sentimentos morais.

Contudo, o rigor na composição do elenco das qualidades e vícios tem relevância limitada no conjunto da investigação, já que o passo decisivo estará em determinar não o conjunto de qualidades e vícios, mas sim porque - no sentido causal da interrogação certo conjunto de qual idades ganha nosso assentimento; os elementos do conjunto dos vícios, porém, nossa aversão. 0 passo decisivo será determinar precisamente os princípios que regem nossas preferências morais.

Também nesse tocante, o procedimento será empírico. 
D ado que esta é uma questão factual e não um assunto de ciência abstrata, só podemos esperar obter sucesso seguindo o método experimental e deduzindo máximas gerais a partir de uma comparação de casos particulares. (HumE, 1995, p. 26)

O s casos particulares serão precisamente as qualidades estimáveis e as condenáveis, a partir das quais espera H ume "atingir o fundamento da ética e descobrir aqueles princípios universais dos quais se deriva, em última instância, toda censura ou aprovação" (HuME, 1995, p. 26).

\section{0 princípio}

Todo o esforço de H ume dedicado ao estudo das qualidades sociais mais importantes - a benevolência e a justiça, e também ao estudo das mais elevadas qualidades que constituem o "mérito pessoal" - resultou para ele na identificação de um único e fundamental princípio para a moral humana, a saber: a utilidade.

A todos os atributos que pudermos elencar sob o título elogioso de virtude, isto é, a todos que concedermos nossa aprovação e valorizarmos como qualidades morais, a eles estará ligada al guma utilidade, seja para o benefício do próprio indivíduo, seja para o benefício da sociedade em que vive. A utilidade acompanha todas as atitudes e ações que, do ponto de vista moral, louvamos. É isso o que mostra o estudo de casos que Hume apresenta a partir da segunda seção até a conclusão de seu pequeno livro.

A ssim é que, no que concerne às virtudes sociais, 0 benevolente ganha nossa admiração e respeito, porque se ocupa em promover 0 interesse dos demais e com isso traz felicidade e satisfação à sociedade. A justiça, cuja existência entre os homens só faz sentido em situações específicas, carecendo de qualquer significado em circunstâncias de extrema necessidade ou grande abundância, tem sua origem na utilidade pública que a sua 
observância acarreta. Sobre o fundamento dessas virtudes, anota Hume:

Q ue fundação mais sólida poder-se-ia desejar ou conceber para qual quer dever do que a observação de que a sociedade humana, e mesmo a natureza humana, não poderá subsistir sem seu estabelecimento, e chegará a graus ain da mais el evados de felicidade e perfeição quanto mais inviolável for 0 respeito dedicado àquele dever? (HuME, 1995, p. 59)

A utilidade dessas virtudes morais é de tal ordem que sem elas não subsistiria a convivência social. Do mesmo modo, os governos e instituições somente encontram justificativa e val or por serem úteis.

É óbvio que o governo jamais teria surgido se fosse completamente inútil, e que o único fundamento do dever de obediência è a vantagem que proporciona à sociedade ao preservar a paz e a ordem entre os seres humanos. (H umE, 1995, p. 65-66)

$E$, para H ume, a vida em sociedade é uma exigência para a própria sobrevivência da espécie humana, o que aponta claramente a dimensão do ben efício ea utilidade que têm as instituições sociais e as virtudes morais que lhe dão sustentação.

Em igual medida, dirá ainda Hume, também as qualidades pessoais são medidas, quanto ao seu valor positivo ou negativo, pelo metro da utilidade. Assim se entende o louvor a qualidades como tenacidade, honestidade, discrição, diligência, prudência, perseverança e tantas outras. Tais atributos nos preparam melhor para viver no mundo, para nele vivermos bem. 0 s benefícios que trazem àqueles que os possuem são a verdadeira origem de sua manifestação entre os homens.

Considerando o peso que dá H ume à utilidade, poderíamos ficar tentados a pensar que sua filosofia moral seria a expressão mais acabada da natureza egoísta do homem. $\mathrm{N}$ ada estaria mais 
distante de ser uma boa interpretação de seu pensamento, cujo otimismo no tocante à boa índole da natureza humana é enorme. Contudo, para a defesa contra esse imerecido achaque, uma outra dimensão ainda não adequadamente explorada da filosofia moral de $\mathrm{H}$ ume tem de ser trazida à tona.

De fato, uma quase obsessão de Hume ao longo de U ma investigação sobre os fundamentos da moral é recusar a idéia de que o princípio da moral seja o egoísmo. Sobre esse pressuposto está erigido o ceticismo que ele decididamente critica e toda a concepção que vê no amor a si o fundamento da moralidade. Com efeito, se a utilidade éo princípio original de toda a moralidade, eesse princípio se define pelo benefício que a posse de algum atributo pode trazer àquele que o possui, então está à mão pensar queéracional escolher ter esses atributos e não outros. A escolha se daria com base em um cálculo de vantagens, cujo índice regulador seria sempre o próprio indivíduo. 0 esquema funciona bem desde que se aceite 0 pressuposto de que agimos motivados fundamental mente pela razão. M as é precisamente esta idéia de que temos, nós humanos, uma razão prática que nos pode motivar - no sentido de que ela seja causa do agir - ações e escolhas é que é absolutamente estranha à filosofia humeana.

Nenhum raciocínio pode induzir-nos a agir numa certa direção, se ali, para onde a ação nos dirige, não houver algo que nos desperte 0 interesse. Embora a razão seja imprescindível para nos ajudar a discernir, na trama dos acontecimentos, como al cançar o que para nós é útil, a utilidade, ela mesma, não se define senão contra o pano de fundo de nossos interesses e inclinações. Cito Hume:

Mas embora a razão, quando plenamente desenvolvida e cultivada, seja suficiente para nos fazer reconhecer a tendência útil ou nociva de atributos e ações, ela sozinha não basta para originar qualquer censura ou aprovação moral. A utilidade é apenas a tendências para atinge um 
certo fim, e, se esse fim nos fosse de todo indiferente, a mesma indiferença seria experimentada em relação aos meios. É preciso aqui que um sentimento venha a se manifestar, para que se estabeleça a preferência pelas tendências úteis diante das nocivas. (HuME, 1995, p. 175)

O sentimento, e não a razão, é que se constitui, segundo a natureza humana, a agulha que orienta nossas escolhas e que, com isso, anima nossa vontade para que nos coloquemos em movimento na direção de nossas preferências.

M as em que isso depõe agora em favor de H ume na disputa contra a tese egoísta? Bem, se não tivermos, por natureza, uma inclinação para promover o bem alheio, se isso não for motivo de satisfação para o indivíduo, então nenhum raciocínio nos poderá levar à vida em sociedade. Só para aquel eque crê numa razão prática é que é concebível a idéia de uma sociedade de diabos. Não para H ume. Em igual medida, se a utilidade e ben efício que nos rendem as virtudes não nos forem agradáveise, por isso, objeto de interesse, nenhuma dedução ou maquinação racional nos poderia motivar a sermos virtuosos. Para que as sementes da virtude lancem em nós suas raízes, é preciso que encontrem um solo propício, é preciso que sejam lançadas na terra fértil do sentimento.

Esse sentimento não pode ser senão um interesse pela felicidade dos seres humanos e uma indignação perante sua desgraça, já que estes são os diferentes fins que a virtude e 0 vício têm tendência a promover. (Hume, 1995, p. 175)

0 que é útil tem de agradar, sob pena de sermos a ele indiferentes. M as não o somos, e para prová-lo, não o recurso a alguma engen haria argumentativa é requerido, mas a observação dos fatos. O s homens vivem em sociedade, associam-se, não são indiferentes ao sofrimento dos outros e sentem satisfação com a promoção do bem alheio, mesmo que seja porque com isso tornam-se merecedores de reconhecimento público. Não importa que 0 
interesse esteja fundado em uma satisfação do indivíduo. Afinal, em que mais elese poderia fundar? M as isso não o torna moralmente condenável. Pelo contrário, a moral somente é possível porque somos de tal modo constituídos que as virtudes nos podem trazer satisfação e agrado, e com isso ganhar nossos sentimentos de aprovação.

Sim, para retomar uma analogia já referida no início deste texto e para o escândalo do moralista, a moral é uma questão de gosto. Ela tem de ter para nós um apelo estético, tem de agradar. $N$ ão obstante, no que tange ao gosto, uma diferença fundamental a separa da apreciação da arte. N a moral, à distinção da estética, 0 útil é que motiva e desperta o sentimento de agradável, já na arte, a utilidade não tem qualquer relevância.

\section{A conclusão}

Para terminar, deixe-me anotar duas observações. U ma sobre o método empirista utilizado por H ume em U ma investigação sobre os princípios da moral, e outra sobre o escopo e caráter da universalidade que, com a concepção humeana da moral, ganhamos para a pretensão de validade dos juízos morais.

Do modo como vejo, o livro é um modelo de como proceder metodologicamente na investigação da moral. 0 preço que se tem de pagar por essa opção metodológica, no entanto, é o abandono da disposição para extrair conseqüências normativas da investigação e o correlato contentamento com o esclarecimento descritivo do fenômeno moral. ${ }^{1}$ É interessante notar que no livro não há nenhuma frase normativa. Não se diz que devemos gostar do útil, mas que é simplesmente assim. A argumentação se deixa resumir mais ou menos do seguinte modo. Se por ventura não tivéssemos por natureza a inclinação para gostar do que é útil, não haveria moral, ou pelo menos ela seria algo muito diferente, se, por exemplo, tivéssemos a inclinação para gostar do que não nos éútil. 
0 que parece francamente absurdo, pois, neste caso, a moral nos teria levado à extinção. ${ }^{2}$ Seria absurdo não gostar do que é útil.

M as o critério para que al go recaia sob o conjunto das coisas que são úteis não éalgo extremamente aberto? Isso não nos previne de uma universalização conseqüente do princípio fundamental da moral humeana? A essas perguntas junto a minha última observação. A vaguidade na determinação da utilidade só nos previne de universalizar valores, não de supor que há uma base universal sobre a qual se edificam todos valores, por diferentes que sejam em cada sociedade. A universilidade a que se almeja com o tratamento empirista enatural izado da moral não é a universalidade da norma, mas dos resultados da observação feita; logo, a validade objetiva do conhecimento adquirido. A recusa ao cético não é feita com base em redes de argumentos, mas por demonstração de que as coisas não se comportam como se poderia esperar que fosse o caso se ele tivesse razão. 0 que se diz contra os céticos é que eles erram no que tange à natureza humana, que suas teses não correspondem aos fatos. C ontudo, porque a opção metodológica contra o relativismo de ten dência cética não tem perfil normativo, mas apenas descritivo, não se pode tirar da cartola do empirismo moral nenhum princípio universal como regra do agir. Esse seria um coel ho metafísico. Princípio, vale finalmente lembrar, é, sob a perspectiva empirista que estou imputando a H ume, tão-somente aquilo que, no plano dos eventos sublunares, conta como causa de nosso agir. Que uma regra possa, pois, ocupar o posto de princípio, é coisa que, para H ume, jamais metafísica al guma poderá provar. Regras não motivam, isso étarefa dos sentimentos. Esta me pareceuma razoável afirmação.

ABSTRACT: W hat I intend to defend on this text is that an empiricist position concern moral is compatible, in some extension, with a pretension that moral judgements are intersubjectively valid. AsI see, this pretension must be based on the naturalisation of the moral's grounds. To defend this point I analyse Hume's philosophy of moral as he presents it at his $\mathrm{A} n$ enquiry concerning the principles of morals. $\mathrm{O} n$ what concerns $\mathrm{H}$ ume's masterpiece myinterest is to make explicit the empirical character of both: his method of investigations, and the moral's principles he found. 
Key words: moral judgements, moral justification, H ume, empiricism.

\section{N otas}

1 No tocante a isso, o livro é insatisfatório, pois muitos temas fundamentais para a compreensão desse fenômeno não são ventilados, tais como o poder, a vontade, o papel da argumentação, a política ea obrigação, além do esclarecimento de sob que artifícios, senão por uma força transcendente, se justifica a validade normativa dos juízos morais.

2 Para a utilidade há, pois, al gum critério de objetividade.

\section{R eferências}

Hume, D. U ma investigação dos princípios da moral. Campinas: U nicamp, 1995.

Russell, B. A filosofia do atomismo lógico. São Paulo: A bril Cultural, 1978.

Nietzsche, F. A genealogia da moral. São Paulo: Moraes, 1985. 